\title{
Human Physiology in Extreme Heat and Cold
}

\section{Braian M Beker, Camila Cervellera, Antonella De Vito and Carlos G Musso*}

Human Physiology Department, Instituto Universitario del Hospital Italiano de Buenos Aires, Argentina

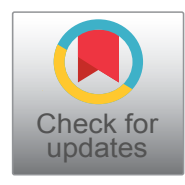

*Corresponding author: Carlos G Musso, Human Physiology Department, Instituto Universitario del Hospital Italiano de Buenos Aires, Argentina, E-mail: carlos.musso@hospitalitaliano.org.ar

\begin{abstract}
The interest in the human body physiological capacity to adapt to extreme heat and cold conditions has increased enormously in the last few decades because of global warming and the consequent changing temperatures. The human body has multiple thermoregulatory mechanisms to counter the external extreme temperatures whose main objective is to keep temperature homeostasis within normal values. As exposure time to these stressful conditions increases and the external temperature becomes even more extreme, the body systems start adapting to its environment progressively. All of the adaptations, at the beginning of the exposure somewhat irrelevant, may become very important since they can affect all of the body systems in a negative manner and finally, compromise life. Clinically, all of these responses and adaptations are manifested through clinical signs and symptoms. The purpose of this paper is to discuss how human physiology adapts during extreme heat and cold conditions to maintain temperature homeostasis and its consequences when this cannot be achieved.
\end{abstract}

\section{Keywords}

Body temperature, Extreme cold, Extreme heat

\section{Introduction}

In any given environment, for any life form to survive, certain requirements are needed but even in the most adverse conditions, what will surely separate the organism's fate from life and death, it is its capacity to adapt to its setting. The human body is well known for its ability to acclimatize to adverse and unfavourable conditions. It is well documented how many humans managed to survive several days in the extreme coldness of the Arctic (e.g. World War II European campaigns) or the severe heat weather climates (e.g. World War II Pacific and North African campaigns) without adequate equipment, pushing humans physiological limits [1-3]. Human beings can often tolerate extreme temperatures well above their thermal balance limits for abbreviated exposure times, which may vary depending on the individual's thermoregulatory response robustness and the environmental characteristics. Described clinical cases have backed up this argument [4].

Temperature is a variable that plays a crucial role in human's health and the diseases it suffers. Because of its importance, body temperature homeostasis is of paramount relevance for optimal cellular function and therefore, human's species subsistence. In medicine, and especially when talking about physiology and how it is affected by temperature, internal organ temperature is the most relevant aspect to take into consideration. This internal organ temperature is referred as body core temperature $\left(T_{c}\right)$. Although measurement of the pulmonary artery temperature through a thermistor seems to be the gold standard, rectal thermometry has evolved as the clinical standard method for determining core temperature [1]. From now on, body temperature and body core temperature will be used indifferently and when referring to temperature, we will be referring to ambient temperature, which is defined as the temperature of the surrounding environment, unaltered by direct human intervention [5].

Climate change is widely acknowledged to be one of the most serious global threats to future human population health and international development because of the impact it has on earth's surface temperature [6]. Although not all extreme temperature scenarios, which affect human beings, are caused by the former, this topic has brought considerable attention in health, climate and policy arenas because it does play a very important role. A vast amount of research is emerging, evidencing

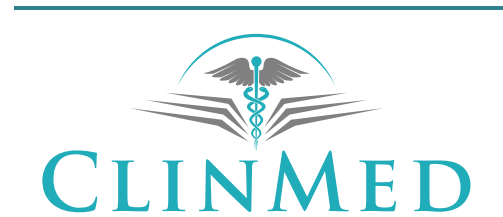

Citation: Beker BM, Cervellera C, De Vito A, Musso CG (2018) Human Physiology in Extreme Heat and Cold. Int Arch Clin Physiol 1:001.

Received: September 18, 2017: Accepted: March 29, 2018: Published: March 31, 2018

Copyright: (c) 2018 Beker BM, et al. This is an open-access article distributed under the terms of the Creative Commons Attribution License, which permits unrestricted use, distribution, and INTER NATIONAL LIBRARY reproduction in any medium, provided the original author and source are credited. 
how it affects world temperature but more importantly, the negative consequences it has on humankind. The extreme ambient temperatures will present major challenges to human adaptation capacity to maintain safe $T_{c^{\prime}}$ preventing fatal consequences. How global warming is originated and how it ends up affecting human population exceeds the aim of this review, hence this topic will not be deepened and additional information can be found in other reference material [7].

All the human systems play, to greater or lesser extent, a role in adapting to extreme temperatures to maintain body temperature homeostasis. When in a cold environment, all the body systems synergize in order to maintain heat and prevent its loss. The opposite case occurs when a person is under hot environmental stress, where the main goal of the body is to adapt to facilitate heat dissipation to prevent elevated, and therefore, dangerous $T_{c}$. The aim of this review is to provide an evidence-based update of the physiological adaptations that cope with extreme hot and cold environments.

\section{Body temperature regulation}

There are three main ways by which human temperature is affected and, in response, regulated $[1,6]$.

Firstly, body temperature is greatly influenced by climate temperature and its characteristics. A stable climate maintains temperatures across most of the surface of planet Earth within a range compatible with human life. As climate temperature is constantly changing and temperature homeostasis is a priority, the second mechanism by which body temperature is regulated takes place. The second way is by the autonomic nervous system, which reacts robustly to thermal challenges by orchestrating a complex array of neural responses below the level of conscious awareness. The third, and perhaps the least predictable, is human behavioural temperature regulation; which responds to thermal sensory input by seeking warmth or coolness, slowing down or stepping up, discontinuing or increasing exercise and removing/adding clothing/equipment; countering its current environment temperature. Simultaneously, it is also responsible for getting people into situations of cold or heat stress, some of which can threaten life or health $[1,3]$. Behavioural thermoregulation will not be described any further and can be assessed elsewhere.

Thermoregulation, the second mechanism described, is a fundamental capacity of the autonomic nervous system to respond to cold and heat stress conditions [1]. Thermoregulatory physiology main goal is to keep a $\mathrm{T}_{\mathrm{c}}$ within a degree or two of $37^{\circ} \mathrm{C}$ and it works because of a coordinated set of autonomic responses to maintain equilibrium between heat production (produced by metabolism primarily) and its dissipation. This physiological characteristic preserves people's health by enabling normal cellular function [8]. $T_{c}$ can range from $36.0-40.0^{\circ} \mathrm{C}$ as a consequence of physical activity, clothing, heat acclimation, circadian rhythms and, what we will be referring here, environmental conditions [9].

If neural thermoregulatory mechanisms fail or if exposure to extreme temperatures is sustained, the thermoregulatory capacity will fail sooner or later leading to body temperatures far from normothermia and finally, to life-threatening situations because of the loss of correct cellular function and their damage [1].

The two most paradigmatic life-menacing states, temperature related, are hyperthermia and hypothermia.

Hyperthermia definition may vary. Some authors define it as an elevated core temperature of $40.5^{\circ} \mathrm{C}$ or more because of a failure of thermoregulation due to an increase in heat production that overwhelms the heat dissipating mechanisms $[1,10]$. Other authors, such as Bouchama \& Knochel [8], define hyperthermia as "a rise in body temperature above the hypothalamic set point when heat-dissipating mechanisms are impaired (by drugs or disease) or overwhelmed by external (environmental or induced) or internal (metabolic) heat" [8]. Although both definitions can be considered complementary, we will be using the former definition since it can be clinically demonstrated. According to Cheshire, it is clinically manifested by "sweating, flushing, tachycardia, fatigue, light-headedness, headache, paraesthesia, muscle cramps, oliguria, nausea, agitation, hypotension, syncope, confusion, delirium, seizures, and finally, coma" [1].

Heat exhaustion and its progression, heatstroke, along with dehydration and electrolyte disorders; are common during heat waves and are known to considerably increase hospital admissions [11].

The recent elevations in climate temperature are becoming a public health issue due to the strong association between temperature rise and mortality. Climate change is one of the main causes of the increasing temperatures contributing to an increase in mortality, especially in frail elderly and infants, where the first week of life is the most critical window of vulnerability $[12,13]$.

Hypothermia, which is a disorder where body core temperature decreases below $35^{\circ} \mathrm{C}$, may be caused by a failure in the production of heat and/or due to an excess in the loss of it [14]. The clinical presentation of hypothermia depends on the intensity and duration of the signs and symptoms of possible associated pathologies. Cheshire states that "it may present with shivering, respiratory depression, cardiac dysrhythmias, impaired mental function, mydriasis, hypotension, and muscle dysfunction, which can progress to cardiac arrest or coma" [1]. Related diseases also influence the prognosis. When hypothermia occurs in isolation, mortality is $6-10 \%$; however, when it is associated with other pa- 
thologies, mortality can reach up to $75 \%$ [15].

In each of these stressful environmental situations, each one of the body systems, try by all their means and mechanisms to counter the environmental temperature and achieve normothermia.

All of the main human systems (cardiovascular, nervous, gastrointestinal, renal, hematologic and tegumentary) are tightly coordinated by the thermostat of the body. This thermostat, located in the preoptic area (POA) of the hypothalamus, is an integration site of the thermosensory information from thermoreceptors located in the skin, muscles, spinal cord and body core; to adjust physiologic responses to gain heat or lose it accordingly [10]. A modification of the blood temperature less than $1{ }^{\circ} \mathrm{C}$ can be signalled to the hypothalamic thermoregulatory centre manifesting with physiological responses to maintain temperature homeostasis [16].

\section{Effects of extreme cold in the organism}

In the cardiovascular system, at the beginning of hypothermia, the sympathetic tone increases due to the decrease in body core temperature secondary to the cold stressful environment. The sympathetic nervous system activates mechanisms, through its impulses transmitted by the sympathetic nerves and the increased liberation of catecholamines from the adrenal medulla to systemic circulation, for retaining and generating heat. Because alpha-adrenoceptors are stimulated, heat conservation is promoted via cutaneous vascular constriction and by decreased peripheral perfusion to prioritize vital organ perfusion, at the expense of a decline in skin and muscle temperature $[17,18]$. Although this response helps in delaying heat loss while defending core temperature, the blood flow reduction and fall in skin temperature, may probably contribute to the etiology of peripheral cold injuries and loss of manual dexterity [18]. Cold-induced vasodilation (CIVD) is another vasomotor response intimately related, which modulates the effect of peripheral vasoconstriction periodically, increasing blood flow and, as it is believed, preventing cold injuries while improving dexterity and tactile sensitivity [18]. By stimulating beta-adrenoceptors, tremor (which generates heat) and appropriate modifications in cardiac output are performed: Increased chronotropism and inotropism, consequently increasing blood pressure (along with the peripheral vasoconstriction), myocardial oxygen consumption and cardiac output $[17,19]$.

As hypothermia progresses, there is an increasing decay in cardiac output, heart rate and blood pressure (the values of the last cannot be measured below $27^{\circ} \mathrm{C}$ ). Cardiac output decreases as a consequence of bradycardia and hypovolemia. The last is a result of reduced plasma volume and intracellular hyperhydration. Bradycardia, which becomes severe below $32{ }^{\circ} \mathrm{C}$, is a consequence of decreased spontaneous depolarization of pacemaker cells and conduction velocity, leading to, along with bradycardia, heart block and prolongation of $P R, Q R S$ and QT intervals $[19,20]$. With temperatures below $30^{\circ} \mathrm{C}$, atrial fibrillation and ventricular dysrhythmia become common. When body core temperature reaches $25{ }^{\circ} \mathrm{C}$ or less, asystole tends to occur [21]. In deep hypothermia, the cardiac index is generally reduced to values below $1-1.5 \mathrm{l} / \mathrm{min} / \mathrm{m}^{2}[22,23]$.

Initial changes in the respiratory system in response to cold stress are not permanent since core temperature tends to continue dropping. Hyperventilation is the initial response to cold but it is followed with hypoventilation as the extreme cold exposure is maintained. With a decrease in temperature, respiratory rate of 15 to 7 breaths per minutes at $30^{\circ} \mathrm{C}$, may fall up to 7 to 4 breaths per minute at approximately $25^{\circ} \mathrm{C}$ as the brain stem is impaired by hypothermia. Hypoventilation produces an increase in carbon dioxide in blood, finally concluding in respiratory acidosis. Interestingly, respiratory stimulus like hypoxia and carbon dioxide cease to work as respiratory drive when core temperature reaches 20 ${ }^{\circ} \mathrm{C}$. Other respiratory alterations have been observed such as a decrease in ciliary motility, lung compliance, thorax elasticity, increased bronchorrhea, noncardiogenic pulmonary edema and alterations in diaphragm and intercostal muscles contractility $[19,21]$.

Regarding the nervous system, being the brain a vital organ, blood flow to it is prioritized and it increases. As hypothermia continues, there is a progressively decrease in oxygen consumption by the brain and spinal cord to protect them from anoxic injury $[24,25]$. Although in early hypothermia, cerebral blood flow increases, it starts to decrease $6 \%$ to $7 \%$ for each $1{ }^{\circ} \mathrm{C}$ decrease in temperature [20]. Since hypothermia decreases nerve conduction, deep tendon reflexes disappear at core temperatures below $32{ }^{\circ} \mathrm{C}$ [20]. Sensitive nerve endings decrease their conduction too and as temperature continues diminishing, patients may no longer complain of cold [20]. Regarding the electroencephalogram (EEG), abnormal activity may be seen below $32{ }^{\circ} \mathrm{C}$ while below $20^{\circ} \mathrm{C}$, the EEG is compatible with brain death [20].

In the gastrointestinal system, intestinal motility decreases progressively as temperature does too, resulting in acute gastric dilation, distension of the colon and ileus when core temperature falls below $28^{\circ} \mathrm{C}[19,21,26]$. Hypothermic-related serum amylases elevations, leading to oedematous or necrohemorrhagic pancreatitis, is often found in necropsy studies of hypothermic patients [15]. The relationship between pancreatitis and hypothermia has not yet been solved, although it has been implicated in ischemia secondary to shock, previous and abusive alcohol intake or the presence of gallstones $[15,26]$. Other gastrointestinal alterations that can be found in hypothermia are: Multiple punctate erosions of low haemorrhagic (Wischnevsky ulcers) in the stomach, ileum and colon; probably related to the release 
of vasoactive amines such as histamine and serotonin and the reperfusion after the cold-induced collapse of the microvasculature $[15,19,26]$. These Wischnevsky's lesions are seen in $80 \%$ of hypothermic patients [19]. Hypothermia induces secretion of gastric acid and inhibits duodenal bicarbonate secretion leading to mucosal damage in the stomach and duodenum [26]. A reduction of conjugation and debugging of various substrates by the liver is described. This last event occurs because of decreased splenic and hepatic blood flow [15,19].

The effects of extreme cold in the hematologic system consist in an increase of patient's haemoglobin and haematocrit due to hemoconcentration. The human spleen sequesters $200-250 \mathrm{~mL}$ densely packed red blood cells and it is accepted that it has the capacity to release them into the systemic circulation during times of stress, as seen in hypothermia, by contracting the spleen [27]. The consequence of that process is increasing blood's oxygen transport and its viscosity. Spleen contraction seems to be mediated by $\alpha$-adrenoreceptors [27]. Blood viscosity seems to increase $2 \%$ per degree Centigrade drop in temperature [19]. Leukopenia has also been observed with granulocytopenia in severe hypothermia, secondary to splenic and hepatic sequestration and by the direct action of cold on the bone marrow [24]. It has been described marrow suppression and progressive marrow failure in hypothermic patients [26].

Enzymic reactions of both intrinsic and extrinsic pathways of the clotting cascade are directly inhibited by cold and consequently, a coagulopathy can develop [26]. Prothrombin time can be significantly increased even with normal clotting factor levels [26].

Thrombocytopenia and platelet dysfunction are very frequent and the first, is caused by bone marrow suppression and splenic sequestration [20]. There is no clear relationship between disseminated intravascular coagulation (DIC) and hypothermia [24].

In the renal system, hypothermia is usually accompanied by a generally mild degree of renal insufficiency because of renal vasoconstriction, with slight increases in the laboratory values of urea and creatinine that usually resolves without sequela, although in some cases acute tubular necrosis may occur. Exposure to cold, with core temperatures below $32{ }^{\circ} \mathrm{C}$, produces an increase in diuresis (cold diuresis). This event is due to blunted response from the tubules to antidiuretic hormone and the peripheral vasoconstriction that elevates blood pressure [28]. The kidney senses this elevation and ultrafiltration increases to counter high blood pressure through diuresis [20].

Finally, regarding the integumentary system and the musculo esqueletico system, temperatures below $32{ }^{\circ} \mathrm{C}$ activates thermoregulatory mechanisms with the objective of retaining and generating heat: Shivering, cutaneous vasoconstriction and decreased peripheral perfusion [20]. Shivering thermogenesis has been re- ported to be very inefficient since it produces heat near the surface of the body and most of it, is lost to the environment. Only $45 \%$ of the heat produced is retained by the patient [19]. Shivering mechanism ceases at approximately $31{ }^{\circ} \mathrm{C}$ [20]. Brown adipose tissue (BAT) has been considered an important actor against cold stress in human infants through non-shivering thermogenesis (NST). Unfortunately, it was widely believed that this capacity was blunted in adulthood until 2009 when several studies demonstrated that this brown adipose tissue is still present in human adults and that it can be activated through cold exposure. Just 1-2 h of cold exposure (14$17^{\circ} \mathrm{C}$ ) are enough to increase the tissue glucose uptake and fatty acid oxidation, consequently increasing heat production through NST. BAT heat production depends on a mitochondrial process called uncoupled respiration, which is mediated by the uncoupling protein-1 (UCP1), which through a succession of events, concludes in the dissipation of chemical energy in the form of heat [29]. Although most BAT is located in the cervical, parasternal, pre- and para-vertebral regions, it has been recently identified that white adipose tissue (WAT) has the ability to transform into BAT through cold and $\beta$-adrenergic stimulation; a process termed "browning" or "beiging" [29]. While in cold exposure there is a gradual decrease of shivering, NST remains elevated [30].

\section{Effects of extreme heat in the organism}

In contrast to what happens in hypothermia, the objective of the body when in extreme heat environments is heat dissipation. The thermoregulatory processes occur to prevent heat stroke, the main hallmark of hyperthermia. Heat stroke is a life-threatening emergency characterized with multiorgan dysfunction caused by a systemic inflammatory response in which encephalopathy predominates and can lead to death [8].

In several studies, it has been suggested that heat directly induces tissue injury; affecting its cellular processes along with denaturing proteins and liquefying and destabilizing cellular membranes [8,31]. At temperatures superior to $49{ }^{\circ} \mathrm{C}$, all cellular structures are destroyed completely and their necrosis occurs in less than five minutes. If temperatures are lower than $49^{\circ} \mathrm{C}$, cell death is because apoptosis although heat-induced apoptosis pathways have not been identified [8]. As soon as the cell recognizes heating, several cytokines, interleukins and heat shock proteins are released into the bloodstream. Heat shock proteins may have a protective effect on cells [8].

To begin with, regarding the cardiovascular system in hyperthermic states, hypotension and in severe cases, shock, becomes the main cardiovascular characteristic. This hypotension is due to dehydration, increased production of nitric oxide which has a vasodilatory function and a shift of heated blood from central circulation to the peripheral circulation to dissipate heat $[8,20]$. Hypohydration consequently produces cardiovascular strain 
because it reduces cardiac filling pressure, this reduces stroke volume and it generates a compensatory tachycardia [32,33]. As result, circulation becomes hyperdynamic, in order to counter the low blood pressure [8]. Patients may suffer postural syncope [20]. Faced with heat stroke, the body reacts manifesting itself consequently with symptoms and signs such as hypotension and related to heart failure and myocardial injury $[8,20]$. Hypertensive patients seem to have a lower heat tolerance since their heat dissipation capacity is impaired because of decreased circulatory performance to the periphery [34].

Common changes in the electrocardiogram when suffering from extreme hyperthermia include prolonged QT interval, rhythm disturbances, conduction defects and ST segment changes [20].

The respiratory system adaptations to heat are primarily hyperpnea and hypocapnia [35]. An elevation of $\mathrm{T}_{\mathrm{c}}$ by $\sim 1{ }^{\circ} \mathrm{C}$ induces a pattern of ventilation called thermal hyperpnea, accounting for increases in tidal volume and frequency of breathing. This adaptation increases pulmonary ventilation approximately $35 \%$ and venous blood $\mathrm{pH}$ from $\sim 7.38$ to 7.46 , developing progressively a respiratory alkalosis [36]. Hypocapnia seems not to affect the ventilatory response. Although total body heat loss from respiratory evaporation seems to be small compared to heat loss from sweating, hyperthermia-induced hyperventilation may selectively remove heat from the brain. It is not clear if hyperventilation-induced hypocapnia fully accounts for the cerebral hypoperfusion reported in patients under heat stress [37]. Respiratory evaporation can account up to the $46 \%$ of total cephalic heat loss [36].

In the nervous system, since the body is in a stressful condition, the sympathetic nervous system will be greatly activated. Patients suffer from neurologic dysfunction due to neuronal damage. Irreversible neuronal damage begins at a temperature above $40{ }^{\circ} \mathrm{C}$ [1]. Neurologic dysfunction is usually severe (delirium or coma) but it may be also very subtle with emotional imbalances such as irritability, headache, dizziness, fatigue, alternating behaviour or impaired judgement [20]. The neurologic dysfunction may be explained by affected connections in cognitive pathways during hyperthermia. The affected connections in the limbic system (consistent with the emotional imbalances, memory and learning ability), in the dorsolateral prefrontal cortex (related to executive functions such as planning, cognition and reasoning) and the intraparietal sulcus (which is involved in the processing of new information and memory); may explain all of the neurological changes [38]. Other causes of neurologic dysfunction may be direct heat-related neuronal damage, changes in cell signalling, ischemia, oedema, changes in cerebral blood flow and inflammatory changes [38]. Blood-brain-barrier permeability increases generating oedema and allowing potential sub- stances and metabolites to enter into the central nervous system [1,38]. Cerebral blood flow may increase at first but with temperatures above $40-41^{\circ} \mathrm{C}$; cerebral blood flow may fall to baseline or below although this is incompletely understood [38]. The neuromuscular system characterises with muscular weakness and cramps due to electrolyte imbalances [20].

The gastrointestinal changes are manifested clinically with increased nausea, vomiting, mucosal swelling and hepatic injury. Splanchnic blood flow is reduced through vasoconstriction to compensate the decreased central blood volume, consequence of the reduced plasma volume and blood pooled to the skin for heat dissipation [33]. Hepatic insult may be a consequence of the hypoperfusion mentioned, which generates hypoxia and consequently, hepatocytes damage because of reactive oxygen and nitrogen species production [1,8]. Elevation of hepatic enzymes is typically observed (aspartate aminotransferase, alanine aminotransferase, $\mathrm{y}$-glutamyl transpeptidase $(\gamma-G T)$, lactate dehydrogenase (LDH), and total bilirubin) [20]. Intestinal injury, because of the commented damaging processes, may lead to mild to moderate diarrhoea $[1,8]$.

The hematologic system, faced with heat stroke, reacts manifesting itself with clinical thrombocytopenia, disseminated intravascular coagulation (DIC) and prolonged prothrombin time [20]. Heat, as it was mentioned, produces cell injury which, as a response, releases cytokines into systemic circulation mediating fever, leucocytosis, muscle catabolism and activation of endothelial cells [8]. Diffuse disseminated intravascular thrombosis is explained by elevated circulating levels of von Willebrand factor, endotelin, metabolites of nitric oxide, thrombomodulin, intercellular adhesion molecule 1 and soluble E-selectin [8]. The prothrombotic state is a characteristic of heat stroke and may lead to multiorgan failure and lastly, death [1]. The red blood cells become more fragile after being exposed to high temperatures generating their early removal from systemic circulation [20].

In the state of hyperthermia, the renal system manifests itself clinically with oliguria and renal failure [8]. This clinical event and renal injury occurs because of direct thermal injury and hypoperfusion caused by dehydration and vasoconstriction. The compromise of the renal blood flow shares the same goal as the splanchnic vasoconstriction $[20,33]$.

Salt and water can be lost by sweating as much as 2 litters per hour and these hydroelectrolytic imbalances impair thermoregulation mechanisms [8]. The water loss increases the salt concentration in blood which is sensed by the macula densa cells in the juxtaglomerular apparatus releasing renin and activating the renin-angiotensin-aldosterone system (RAAS) to increase the reabsorption of salt and indirectly, water. The osmostat, located in the hypothalamus, senses the osmolality of 
the extracellular fluid which is going to be high, and will release antidiuretic hormone (ADH) which is stored in the posterior pituitary gland. The ADH will increase the expression of aquaporins 2 in apical cell membranes of the kidney's collecting duct principal cells in order to increase the reabsorption of free water [39].

Finally, in the integumentary system, hyperthermia clinical symptoms are sweating and flushing. Both manifestations are a consequence of cutaneous vasodilatation, which dissipates heat by radiant and convective heat loss, and sweating, which produces heat loss by evaporation [1]. The skin is the main organ related to heat dissipation
[28]. Both processes, cutaneous vasodilatation and the consequent heat loss, are produced by the previously mentioned sympathetic nervous system activation. When activated, eccrine sweat glands increase their sweat production cooling the body [23]. The highest reported sweating rate is attributed to Alberto Salazar, an American Olympic distance runner, who sweated $3.7 \mathrm{~L} / \mathrm{h}$ in the 1984 Olympic Marathon [32].

A comparison of human physiological changes in extreme heat and cold is presented in Table 1.

\section{Conclusion}

Table 1: Human physiology changes in extreme heat and cold.

\begin{tabular}{|c|c|c|}
\hline Body systems & Extreme cold & Extreme heat \\
\hline Cardiovascular & $\begin{array}{l}\text { - Peripheral vasoconstriction with blood shift to central } \\
\text { circulation } \\
\text { - In early hypothermia: } \\
\text { o Increased inotropism and chronotropism } \\
\text { o Increased cardiac output and blood pressure } \\
\text { - At late hypothermia: } \\
\text { O Decreased chronotropism and inotropism } \\
\text { o Decreased cardiac output and blood pressure } \\
\text { ECG disturbances (bradycardia, heart block and } \\
\text { prolongation of PR, QRS and QT intervals) }\end{array}$ & $\begin{array}{l}\text { - Peripheral vasodilatation with blood shift from } \\
\text { - } \text { Dentral to peripheral circulation } \\
\text { cases, shock } \\
\text { - Hyperdynamic circulation: Tachycardia and } \\
\text { increased cardiac output } \\
\text { - ECG disturbances (prolonged QT interval, } \\
\text { rhythm disturbances, conduction defects and } \\
\text { ST segment changes) }\end{array}$ \\
\hline Respiratory & $\begin{array}{l}\text { - In early hypothermia: } \\
\text { - At late hypothermia: } \\
\text { o Hypoventilation } \\
\text { - Hypercapnia and pulmonary acidosis, secondary to } \\
\text { hypoventilation } \\
\text { - Decreased: } \\
\text { o Ciliary motility } \\
\text { o Lung compliance } \\
\text { o Thorax elasticity } \\
\text { Increased: } \\
\text { o Bronchorrhea } \\
\text { o Noncardiogenic pulmonary edema } \\
\text { Alterations in diaphragm and intercostal muscles } \\
\text { contractility }\end{array}$ & $\begin{array}{l}\text { - Thermal-hyperpnea (increases in tidal volume } \\
\text { and frequency of breathing) } \\
\text { - Hypocapnia and pulmonary alkalosis, } \\
\text { secondary to hyperventilation } \\
\text { - Brain heat dissipation secondary to } \\
\text { respiratory evaporation }\end{array}$ \\
\hline Neuromuscular & $\begin{array}{l}\text { - } \text { - At first, blood flow to the brain increases but starts } \\
\text { decreasing steadily } \\
\text { - Increased muscular tremor to produce heat at early } \\
\text { stages } \\
\text { - Decreased nerve conduction: } \\
\text { o Decreased sensitivity } \\
\text { o Decreased deep tendon reflexes }\end{array}$ & $\begin{array}{l}\text { - } \text { Great activation of sympathetic nervous } \\
\text { system } \\
\text { - At first, blood flow to the brain increases but } \\
\text { - } \text { Increarts decreasing as temperature rises } \\
\text { - } \text { Muscular weakness and cramps } \\
\text { - Neurologic dysfunction to irreversible } \\
\text { neuronal damage }\end{array}$ \\
\hline Digestive & $\begin{array}{l}\text { - Gastrointestinal organs injury secondary to } \\
\text { hypoperfusion: } \\
\text { o Splenic and hepatic insult. Decreased function of } \\
\text { the last } \\
\text { - Decreased intestinal motility, leading to ileus and } \\
\text { internal organs distention } \\
\text { - Mucosal damage and erosions in stomach, duodenum, } \\
\text { ileum and colon } \\
\text { - Pancreatitis secondary to hypothermic-related serum } \\
\text { amylase elevations }\end{array}$ & $\begin{array}{l}\text { - Gastrointestinal organs injury secondary to } \\
\text { hypoperfusion: } \\
\text { - Hepatic insult with consequent enzymes } \\
\text { elevations } \\
\text { - Intestinal injury may lead to diarrhea }\end{array}$ \\
\hline
\end{tabular}




\begin{tabular}{|c|c|c|}
\hline Hematologic & $\begin{array}{l}\text { - } \text { Clinical manifestations of thrombocytopenia } \\
\text { - Increased disseminated intravascular coagulation } \\
\text { - Increased prothrombin time } \\
\text { - Increased hemoconcrentation and hence, hematocrit } \\
\text { - } \text { Spleen contraction increases circulating erythrocytes } \\
\text { - Increased leukopenia } \\
\text { - Increased bone marrow supression } \\
\text { Increased blood viscosity }\end{array}$ & $\begin{array}{l}\text { - } \text { Clinical manifestations of thrombocytopenia } \\
\text { - Increased disseminated intravascular } \\
\text { coagulation } \\
\text { - Increased prothrombin time } \\
\text { Early removal of red blood cells from } \\
\text { circulation }\end{array}$ \\
\hline Renal & $\begin{array}{l}\text { - Increase of cold diuresis } \\
\text { - Mild degree of renal insufficiency due to renal } \\
\text { vasoconstriction }\end{array}$ & $\begin{array}{l}\text { - Oliguria } \\
\text { - Renal injury and insufficiency due to } \\
\text { direct thermal damage and hypoperfusion } \\
\text { (dehydration and blood shift to the skin) } \\
\text { - Activation of the renin-angiotensin- } \\
\text { aldosterone system }\end{array}$ \\
\hline Integumentary & $\begin{array}{l}\text { - Increased cutaneous vasoconstriction } \\
\text { - Decreased sweat production by eccrine sweat glands } \\
\text { - Increased non-shivering thermogenesis through brown } \\
\text { adipose tissue }\end{array}$ & $\begin{array}{l}\text { - Increased cutaneous vasodilatation } \\
\text { - Increased sweat production by eccrine sweat } \\
\text { glands with the consequent loss of water and } \\
\text { electrolytes }\end{array}$ \\
\hline
\end{tabular}

The thermoregulatory responses and processes after the human body is exposed to extreme heat and cold are very complex. All of these processes occur with the final objective of keeping temperature homeostasis within normal values. When the body is exposed to extreme heat conditions, the body most important mechanism to dissipate heat and prevent an increase in core temperature is sweating but when in cold conditions, in order to prevent hypothermia, the body's main objective is heat conservation predominantly through peripheral vasoconstriction to shift blood from the periphery to the internal and vital organs. In early stages, this can be achieved but depending on the extreme temperatures the body is exposed to and the duration of the exposure, sooner or later the thermoregulatory mechanisms will begin to fail manifesting in clinical signs and symptoms and finally death. The human body is prepared with a lot of mechanisms to protect from these extreme temperatures and to reach homeostasis but never for too long in such extreme conditions. Further evidence and research is needed to comprehend physiological limitations to extreme temperatures and for a broader understanding of the measures needed to prevent situations where health, and even life, is at risk.

\section{References}

1. Cheshire WP Jr (2016) Thermoregulatory disorders and illness related to heat and cold stress. Auton Neurosci 196: 91-104.

2. Department of the Army (2005) TB MED 508: Prevention and management of cold-weather injuries. Washington, DC.

3. Department of the Army and Air Force (2003) TB-MED 507: Heat stress control and heat casualty management. Government Printing Office, Washington, DC.

4. Kenney WL, DeGroot DW, Holowatz LA (2004) Extremes of human heat tolerance: Life at the precipice of thermoregulatory failure. J Therm Biol 29: 479-485.

5. Oxford Dictionaries. Oxford University Press, Oxford, England.

6. Mclver L, Kim R, Woodward A, Hales S, Spickett J, et al.
(2016) Health impacts of climate change in pacific island countries: A regional assessment of vulnerabilities and adaptation priorities. Environ Health Perspect 124: 1707-1714.

7. Hanna EG, Tait PW (2015) Limitations to thermoregulation and acclimatization challenge human adaptation to global warming. Int J Environ Res Public Health 12: 8034-8074.

8. Bouchama A, Knochel JP (2002) Heat stroke. N Engl J Med 346: 1978-1988.

9. Potter AW, Blanchard LA, Friedl KE, Cadarette BS, Hoyt RW (2017) Mathematical prediction of core body temperature from environment, activity, and clothing: The heat strain decision aid (HSDA). Journal of Thermal Biology 64: 78-85.

10. Webb A, Angus D, Finfer (2016) Oxford textbook of critical care. ( $2^{\text {nd }}$ edn), Oxford University Press, UK.

11. Vaneckova P, Bambrick H (2013) Cause-specific hospital admissions on hot days in Sydney, Australia. PLoS One 8: e55459.

12. Yonghong Li, Yibin Cheng, Guoquan Cui, Chaoqiong Peng, Yan Xu, et al. (2014) Association between high temperature and mortality in metropolitan areas of four cities in various climatic zones in China: A time-series study. Environ Health 13: 65.

13. Basagaña X, Sartini C, Barrera-Gómez J, Dadvand P, Cunillera J, et al. (2011) Heat waves and cause-specific mortality at all ages. Epidemiology 22: 765-772.

14. Celis Edgard Hipotermia: Guía para urgencias, Capítulo 22. Editorial Panamericana.

15. Fuhrman FA, Crismon JM (1947) The influence of acute hypothermia on the rate of oxygen consumption and glycogen content of the liver and on the blood glucose. Am J Physiol 149: 552.

16. Mackowiak PA (1997) Fever: Basic mechanisms and management. ( $2^{\text {nd }}$ edn), Lippincott-Raven, Philadelphia, 35-40.

17. Subramanian $S$ (2002) The role of the sympathetic nervous system in the acute hypothermic effect of D-fenfluramine. Pittsburgh: University of Pittsburgh.

18. Castellani JW, Young AJ, Ducharme MB, Giesbrecht GG, Glickman E, et al. (2006) American College of Sports Medicine position stand: Prevention of cold injuries during exercise. Med Sci Sports Exerc 38: 2012-2029.

19. Pozos RS, Danzl DF (2002) Human physiological respons- 
es to cold stress and hypothermia. In: KB Pandolf, RE Burr, Textbooks of military medicine: Medical aspects of harsh environments. Falls Church, YA: Office of the Surgeon General, U.S. Army, 1: 351-382.

20. Furhman BP, Zimmerman JJ (2011) Pediatric critical care. ( $4^{\text {th }}$ edn), Elsevier, USA, 1477-1484.

21. Jurkovich GJ (2007) Environmental cold-induced injury. Surg Clin North Am 87: 247-267.

22. Exton-Smith AN (1973) Medicine in old age. Accidental hypothermia. Br Med J 4: 727-729.

23. Harari A, Regnier B, Rapin M, Lemaire F, Le Gall JR (1973) Perturbations hémodynamiques au cours des hypothermies accidentelles profondes et prolongées. Nouv Presse Med 3: 184.

24. Avellanas ML, Laplaza J, Cego-ino J, Monton JM, Seron C (1991) Hipotermia accidental en los accidentes de montaña. Importancia de la rapidezen el rescate y traslado. Med Intensiva 15: 147-153.

25. Benson DW, Williams G Rainey, Spencer Frank C, Yates Adolph J (1959) The use of hypothermia after cardiac arrest. Anesthesia and Analgesia 38: 423-428.

26. ML Mallet (2002) Pathophysiology of accidental hypothermia. QJM 95: 775-785.

27. Baković D, Eterović D, Saratlija-Novaković Z, Palada I, Valic Z, et al. (2005) Effect of human splenic contraction on variation in circulating blood cell counts. Clin Exp Pharmacol Physiol 32: 944-951.

28. Sandhu JS, Agarwal A, Gupta KL, Sakhuja V, Chugh KS (1992) Acute renal failure in severe hypothermia. Ren Fail 14: $591-594$.
29. Fenzl A, Kiefer FW (2014) Brown adipose tissue and thermogenesis. Horm Mol Biol Clin Investig 19: 25-37.

30. van der Lans AA, Hoeks J, Brans B, Guy HEJ Vijgen, Mariëlle GW Visser, et al. (2013) Cold acclimation recruits human brown fat and increases nonshivering thermogenesis. J Clin Invest 123: 3395-3403.

31. Mahant S (2015) The evaluation and management of heat injuries in an intensive care unit. Indian J Crit Care Med 19: 479-483.

32. Kenney WL, DeGroot DW, Holowatz LA (2004) Extremes of human heat tolerance: Life at the precipice of thermoregulatory failure. J Therm Biol 29: 479-485.

33. Goldman RF (2001) Introduction to heat-related problems in military operations. In: Pandolf KB, Burr RE, Medical aspects of harsh environments. Government Printing Office, Washington DC.

34. Havenith G (2005) Temperature regulation, heat balance and climatic stress. Extreme Weather Events and Public Health Responses 69-80.

35. Yousef MK (1972) Physiological adaptations: Desert and mountain. Academic Press, Inc, USA.

36. White MD (2006) Components and mechanisms of thermal hyperpnea. J Appl Physiol (1985) 101: 655-663.

37. Tsuji B, Hayashi K, Kondo N, Nishiyasu T (2016) Characteristics of hyperthermia-induced hyperventilation in humans. Temperature (Austin) 3: 146-160.

38. Walter EJ, Carraretto M (2016) The neurological and cognitive consequences of hyperthermia. Crit Care 20: 199.

39. Eaton DC, Pooler J, Vander AJ (2002) Vander's Renal Physiology. (6 ${ }^{\text {th }}$ edn), McGraw-Hill, New York, NY. 